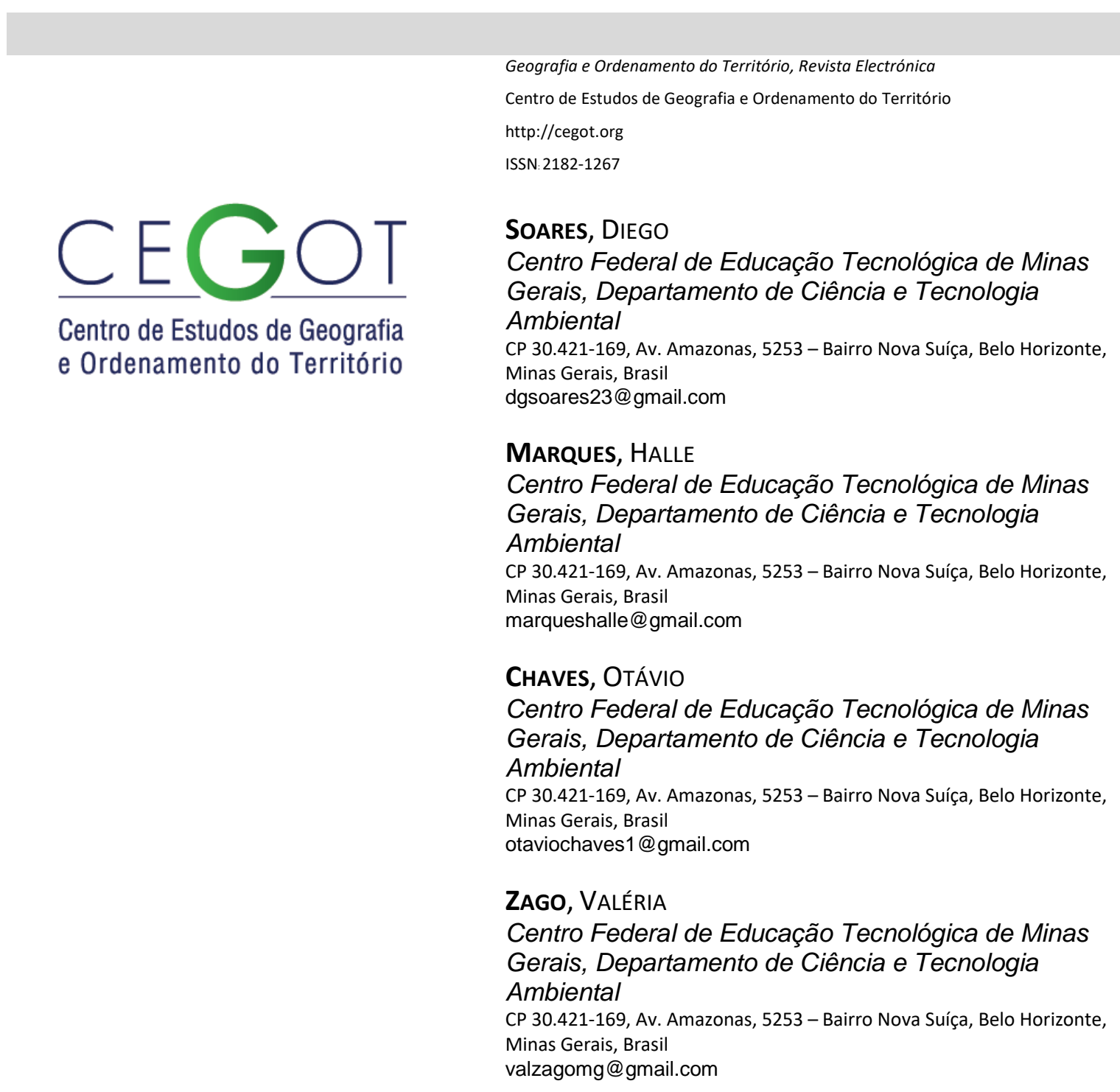

\title{
Diagnóstico para a otimização do sistema de gestão dos resíduos sólidos na Regional Centro-Sul do Município de Belo Horizonte: uma análise das forças e fraquezas, oportunidades e ameaças
}

Diagnosis for the optimization of the solid waste management system in the Center-South Region of the Belo Horizonte city: an analysis of stengths and weaknesses, opportunities and threats

Referência: Soares, Diego et al. (2016). Diagnóstico para a otimização do sistema de gestão dos resíduos sólidos na Regional Centro-Sul do Município de Belo Horizonte: uma análise das forças e fraquezas, oportunidades e ameaças. Revista de Geografia e Ordenamento do Território (GOT), n.o 10 (dezembro). Centro de Estudos de Geografia e Ordenamento do Território, p. 319-343, dx.doi.org/10.17127/got/2016.10.015 


\section{RESUMO}

O presente artigo trata-se de uma análise do sistema de gestão de resíduos sólidos da Regional Centro-Sul de Belo Horizonte, Minas Gerais. O trabalho teve como objetivo fazer uma avaliação das fraquezas, oportunidades e ameaças a esse sistema para, então, propor melhorias. Já a justificativa está nas dificuldades enfrentadas pelo gerenciamento do sistema de coleta, concebido de tal maneira que não integra, como deveria, elementos técnicos às características sociais, econômicas, políticas e espaciais do território. Algumas dessas características se referem a um território de considerável contraste social, que é um polo econômico e político do Estado e que concentra elevados fluxos de pessoas e mercadorias de toda a Região Metropolitana de Belo Horizonte. Para a elaboração da análise foi realizada uma extensa coleta de dados obtidos a partir de diagnóstico em campo e por meio de relatórios e documentos de diversos órgãos oficiais, como a Superintendência de Limpeza Urbana do município. Em uma primeira etapa as informações foram tratadas descritivamente e, algumas delas, foram espacializadas em um ambiente SIG (Sistema de Informações Geográficas). Isso contribuiu para, em uma segunda etapa, realizar uma análise SWOT (Forças, Fraquezas, Oportunidades e Ameaças) que indicou questões a serem tratadas a fim de otimizar o sistema. Um dos desafios apontados foi a necessidade de integrar o sistema de gestão da região com o das regiões circunvizinhas, o que pode requisitar um planejamento urbano mais colaborativo.

Palavras-chave: Planejamento Urbano, Análise SWOT, Resíduos Sólidos, Gestão Integrada.

\section{ABSTRACT}

This article is an analysis of the solid waste management in Central-South region of Belo Horizonte, Minas Gerais. The study aimed to evaluate the weaknesses, opportunities and threats to the system to then propose improvements. The justification is on the difficulties faced by the management of the collection system, designed in such a way that does not integrate, as it should, technical elements to the social, economic, political and spatial characteristics of the territory. Some of these features refer to a territory with a considerable social contrast, that is a political and economic hub of the state and that concentrates high flows of people and products in the metropolitan region of Belo Horizonte. For the analysis was performed an extensive collection of data from field diagnostic and through reports and documents of various official bodies, such as municipal Superintendence of Urban Sanitation. In a first step the information were handled descriptively and some of them were spatialized in a GIS (Geographic Information System). In a second step, contributes to perform an analysis SWOT (Strengths, Weaknesses, Opportunities and Threats) which indicated issues to be covered in order to optimize the system. One of the challenges indicated was the need to integrate the management system of the region with the management systems of neighboring regions, which can request a more collaborative urban planning.

Keywords: Urban Planning, SWOT Analysis, Solid Waste, Integrated Management. 


\section{Introdução}

A gestão de resíduos sólidos será um dos principais desafios para os municípios brasileiros nos próximos anos. A questão ganhou maior relevância em razão da promulgação da Política Nacional dos Resíduos Sólidos - PNRS - instituída pela lei nำ12.305/2010, com a perspectiva de possibilitar ao Brasil, uma evolução frente aos problemas ambientais, sociais e econômicos decorrentes do gerenciamento inadequado dos resíduos sólidos (Baldim, 2016).

Esse marco legal sinaliza a visão moderna da gestão que se pretende alcançar no país, encravada em seus princípios e na definição de suas prioridades em relação aos resíduos sólidos: não geração, redução, reutilização e reciclagem, tratamento dos resíduos e disposição final adequada dos rejeitos (Brasil, 2010).

Para tanto, estabelece uma série de obrigações aos geradores e ao poder público, necessárias para viabilizar a gestão local de resíduos. Dentre elas, a elaboração dos Planos Municipais, condição compulsória para terem acesso aos recursos da União destinados à limpeza urbana e ao manejo de resíduos sólidos, ou para serem beneficiados por incentivos ou financiamentos de entidades federais de crédito ou fomento para tal finalidade (BRASIL, 2010). Até o final de 2015, apenas $41 \%$ dos 5569 municípios tinham elaborado seus planos municipais de resíduos sólidos.

Belo Horizonte é a capital do estado de Minas Gerais, região sudeste do Brasil, possui uma área de aproximadamente $331 \mathrm{~km}^{2}$ e uma população de 2.502 .557 habitantes. O município é considerado pioneiro e modelo na gestão dos resíduos sólidos no país. Durante a década de 90, implementou a coleta seletiva em alguns bairros, tanto no sistema porta a porta, quanto outros equipamentos públicos de entrega voluntária, distribuídos pela cidade, além um Programa de Compostagem (Silva e Barbosa, 2001). No entanto, avançou muito pouco nas últimas décadas, o que se pode constatar a partir dos próprios relatórios anuais de limpeza urbana da cidade.

Segundo o relatório anual de 2015 da Superintendência de Limpeza Urbana - SLU naquele ano $96 \%$ da população foi atendida pelos serviços de limpeza urbana e foram coletados e destinados 1.433.511 toneladas de resíduos sólidos (SLU, 2016). Como os registros quantitativos daquele ano não foram precisos, é possível apenas estimar, baseado em relatórios de anos anteriores, que entre $90-96 \%$ dos resíduos coletados foram 
encaminhados para o aterro sanitário. E, ainda que a maior parte dos resíduos urbanos aterrados sejam provenientes de domicílios e logradouros comerciais, também são aterrados resíduos da construção civil e demolição, resíduos da varrição de espaços públicos e de saúde.

Ao não reciclar os resíduos sólidos, o país deixa de arrecadar cerca de 8 bilhões de reais anualmente (IPEA, 2010). Extrair recursos naturais de um lugar e enterrá-los em outro pode parecer algo ineficiente do ponto de vista econômico; no entanto, é isto que o Brasil vem fazendo com a maior parte dos seus resíduos sólidos. O custo é alto, não apenas pelo desperdício de matéria-prima, mas pelos danos ambientais e à saúde pública (Moura et al, 2015).

De maneira similar à realidade nacional, Belo Horizonte segue a mesma tendência, o que revela a necessidade de diagnosticar as dificuldades e os desafios do processo, a fim de progressivamente avançar na hierarquia preconizada na PNRS para a gestão e gerenciamento dos resíduos sólidos. O município possui uma logística básica, orientada nas etapas do gerenciamento: coleta, transporte, transbordo e disposição final, porém bem distante do preconizado pela PNRS.

Para gerenciar os resíduos sólidos de uma área tão extensa e de uma população tão numerosa, a gestão é dividida em nove regionais administrativas, criadas em 1983. Dentre essas, a regional Centro-Sul de Belo Horizonte apresenta desafios ímpares, já que dentro de suas fronteiras existem características territoriais únicas como disparidades urbanísticas e socioeconômicas contrastantes, além de ter importância política, econômica e populacional para o estado de Minas Gerais. Este cenário gera uma disputa pelos recursos municipais entre os atores regionais. A incompatibilização desses atores se reflete no sistema de gestão de resíduos sólidos, tornando-o particular e justificando a necessidade de uma análise mais aprofundada sobre o processo de gestão de resíduos e sobre a conjuntura que o envolve.

Várias técnicas de análise estão sendo usadas no planejamento estratégico da gestão de resíduos no mundo. O planejamento estratégico é o processo de definição da estratégia, direção e tomada de decisões sobre a alocação de seus recursos, incluindo o capital e as pessoas. Diversas técnicas de análise de negócios pode ser usado no planejamento estratégico da gestão de resíduos sólidos, como por exemplo a análise SWOT (Strengths, Weaknesses, Opportunities e Threats) (UNEP, 2009). Vários países e regiões tem utilizado o método na gestão de resíduos sólidos (MED, 2009; Lisboa, 2016). A análise SWOT 
proporciona o entendimento de forças, fraquezas, oportunidades e ameaças envolvidas em qualquer atividade. Essa abordagem ajuda na especificação dos objetivos por avaliar fatores internos e externos que são favoráveis ou não. Apesar disso, no Brasil, essa ferramenta é muito pouco utilizada pelos gestores públicos, o que justifica uma carência de trabalhos que empreguem o método no país.

Este trabalho objetivou a realização de um diagnóstico através da metodologia SWOT em conjunto com aplicações de SIG - Sistema de Informações Geográficas, a fim de obter informações que auxiliem na tomada de decisões e formulações de propostas para otimizar a gestão de resíduos sólidos na regional Centro-Sul da capital mineira e, posteriormente, ser estendida às demais regionais da cidade.

\section{Metodologia}

O trabalho foi realizado em duas etapas, tal como é demonstrado na figura 1 . A primeira etapa consistiu em levantamento e coleta de informações provindas de literatura científica e de documentos oficiais como censos, planos diretores, planos municipais, leis, mapas temáticos e outros. Esses levantamentos foram obtidos por meio de visitas às páginas eletrônicas e sistemas de disponibilização de dados de diversos órgãos oficiais, a citar: Prefeitura de Belo Horizonte - PBH; Superintendência de Limpeza Urbana de Belo Horizonte - SLU ${ }^{1}$; Secretaria Municipal Adjunta de Planejamento Urbano - SMAPU; Secretaria Municipal de Meio Ambiente - SMMA; Serviço Municipal de Drenagem Urbana - Drenurbs; Conselho Municipal de Saneamento - COMUSA; Empresa de Transporte e Trânsito de Belo Horizonte - BHTrans; Empresa de Informática e Informação - Prodabel; Agência de Desenvolvimento da Região Metropolitana de Belo Horizonte - ADRMBH; Instituto Brasileiro de Geografia e Estatística - IBGE; Instituto de Pesquisa Econômica Aplicada - IPEA; e Ministério do Meio Ambiente - MMA.

\footnotetext{
${ }^{1}$ Os autores deste trabalho, consideram que o apoio da SLU-BH (Sede administrativa) foi fundamental para a obtenção de dados e informações que auxiliaram na construção de cada uma das etapas deste documento. Por tanto, os autores agradecem à entidade.
} 


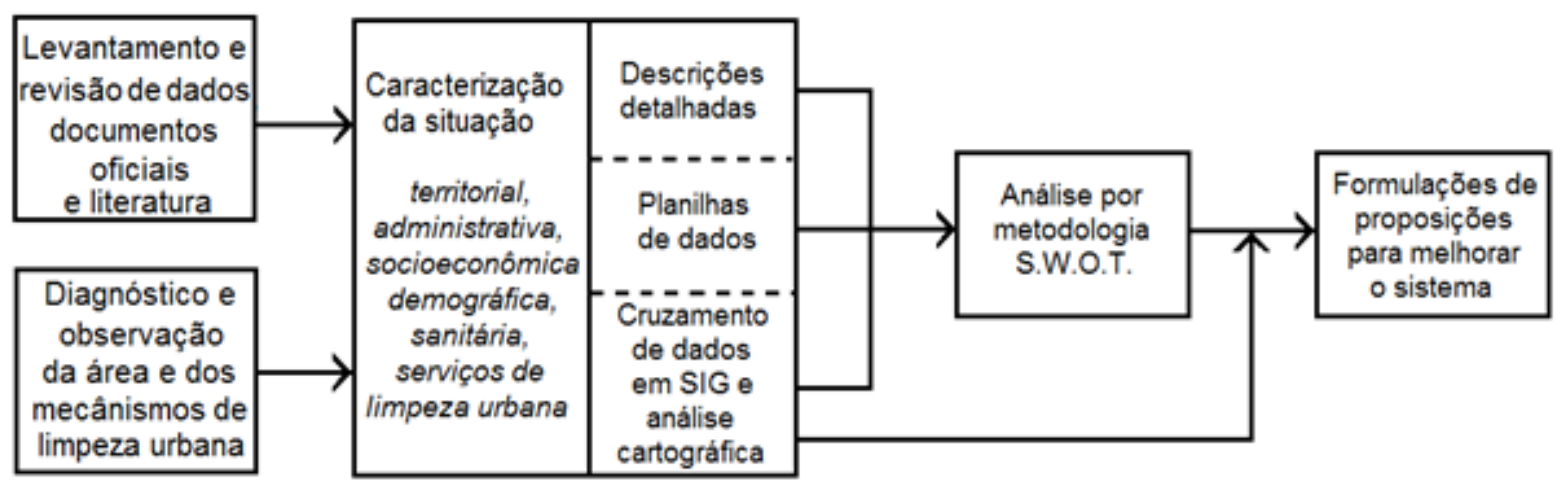

Figura 1 - Esquema metodológico seguido \Fonte: Próprios autores

A partir dessas informações, foi realizada a segunda etapa, na qual se elaborou um diagnóstico da área de estudo (regional Centro-sul) e de seu sistema de recolhimento de resíduos. Para tanto, foi realizada uma visita aos principais equipamentos urbanos da regional e entrevistas com alguns funcionários da SLU, objetivando obter mais informações sobre o sistema. Esta etapa teve como foco encontrar as deficiências mais aparentes do sistema, averiguar como os mecanismos de limpeza funcionam na prática e como a população interage com os mesmos.

Em posse de todos esses dados foi elaborada uma extensa caracterização da regional Centro-Sul. Essa etapa foi sintetizada em três subprodutos: descrições técnicas detalhadas, planilhas de dados e a espacialização dos mesmos em forma gráfica pelo ambiente SIG.

Posteriormente, de posse de todos os dados, foi elaborada a análise SWOT. De acordo com Harisson (2010) e Orea (2008), esta ferramenta ao reunir as informações, correlaciona muitos fatores diferentes para permitir um exame das forças e fraquezas internas de uma organização, bem como suas oportunidades de crescimento e as ameaças que o ambiente externo apresenta em relação a sua sobrevivência. Esse exame pode ser usado para gerar um plano em que o potencial dos pontos fortes e das oportunidades é maximizado para minimizar as deficiências, causadas pelas fraquezas, e os impactos, causados pelas ameaças.

\section{Resultados e Discussões}

Observar significa aplicar os sentidos físicos a um objeto para obter conhecimento sobre ele (Cervo e Bervian, 2002). Uma observação racional e imparcial, quando precedida e embasada por referenciais teóricos, pode levar a resultados mais precisos e ao conhecimento de fatos que, muitas vezes, não são claramente perceptíveis. As primeiras 
observações foram realizadas com o respaldo de dados quantitativos e qualitativos e permitiram realizar as primeiras caracterizações da região Centro-Sul, em relação aos fatores que mais interferem no sistema de coleta de resíduos. Para isso, essa etapa de caracterização teve como eixos de raciocínio análises territoriais, socioeconômicas, demográficas e sanitárias, em especial o que tange os serviços de limpeza urbana.

\subsection{Caracterização}

\section{- Caracterização Territorial}

Desde 1983, o município de Belo Horizonte está dividido em nove regiões administrativas Barreiro, Centro-Sul, Leste, Nordeste, Noroeste, Norte, Oeste, Pampulha e Venda Nova que funcionam como subprefeituras. Estas regionais foram repartidas de acordo com a posição geográfica, as características socioculturais e a ocupação de cada bairro. A intenção é fazer com que os serviços públicos atinjam todo o território e toda a população de forma mais rápida e resolver problemas pontuais de cada regional (Belo Horizonte, 2015).

Em um município tão urbanizado, como Belo Horizonte, o planejamento urbano, mesmo dividido por regionais, ainda é complexo. Desta forma, as regionais foram também subdivididas em Unidades de Planejamento - UP. Segundo a PBH, essas unidades reúnem um ou mais bairros e foram demarcadas de acordo com as características de uso e ocupação do solo. Esse fato é de suma importância, por exemplo, na elaboração das rotas dos caminhões de coleta de resíduos, que são traçadas por UP's. Ainda de acordo com a PBH, a regional Centro-Sul possui 49 bairros repartidos entre 13 Unidades de Planejamento.

A história da região Centro-Sul, segundo os documentos históricos da PBH, confunde-se com a criação da capital mineira em 1891. Como mostra Silva (2008), o traçado inicial da cidade foi planejado e limitava-se a área interna à avenida do Contorno. Com o passar do tempo e o crescimento populacional, a cidade gradativamente expandiu-se para além dessa avenida. Os bairros do Centro, localizados dentro da Avenida do Contorno foram os primeiros a serem planejados, construídos e ocupados. A partir daí, o crescimento de Belo Horizonte se deu a leste, a oeste e ao norte, para mais tarde se conurbar às cidades vizinhas e permitir, na década de 1970, a criação de uma Região Metropolitana.

A região Centro-Sul sempre concentrou o comércio e os serviços da cidade. A partir da década de 80 , esse fato se acentuou ainda mais quando um dos seus maiores bairros residenciais - Savassi - foi se tornando também uma área comercial. Com isso, os imóveis destinados à habitação se converteram em edifícios destinados ao comercio e, por consequência, houve um decréscimo da população dentro da área da Avenida do Contorno 
(Belo Horizonte, 2008). A partir de então, a região se consolidou como referência comercial, financeira e política de grande parte do Estado, apresentando quase $40 \%$ dos imóveis não residenciais do munícipio (Silva, 2008)

Em todo o Brasil, segundo Silva e Travassos (2008), o processo de crescimento urbano acelerado levou ao desenvolvimento de aglomerados e assentamentos a partir da ocupação de áreas de risco e áreas de preservação ambiental. Em Belo Horizonte esse processo teve início ainda nos anos 30 quando os trabalhadores, trazidos para a construção da capital, não puderam retornar ao interior e criaram as primeiras vilas. Com a expansão comercial da região da Savassi o processo migratório foi acentuado. Muitos migrantes, como não conseguiam ocupar as áreas nobres destinadas à habitação, ocuparam as vertentes do bairro Serra e a região da Barragem Santa Lúcia. A região é complexa em termos de gestão urbana. Convivem ali um grande conjunto de favelas, áreas de proteção ambiental, bairros de classe média-alta e atividades de mineração (Silva, 2008). Essa complexidade é vislumbrada no mapa da figura 2.

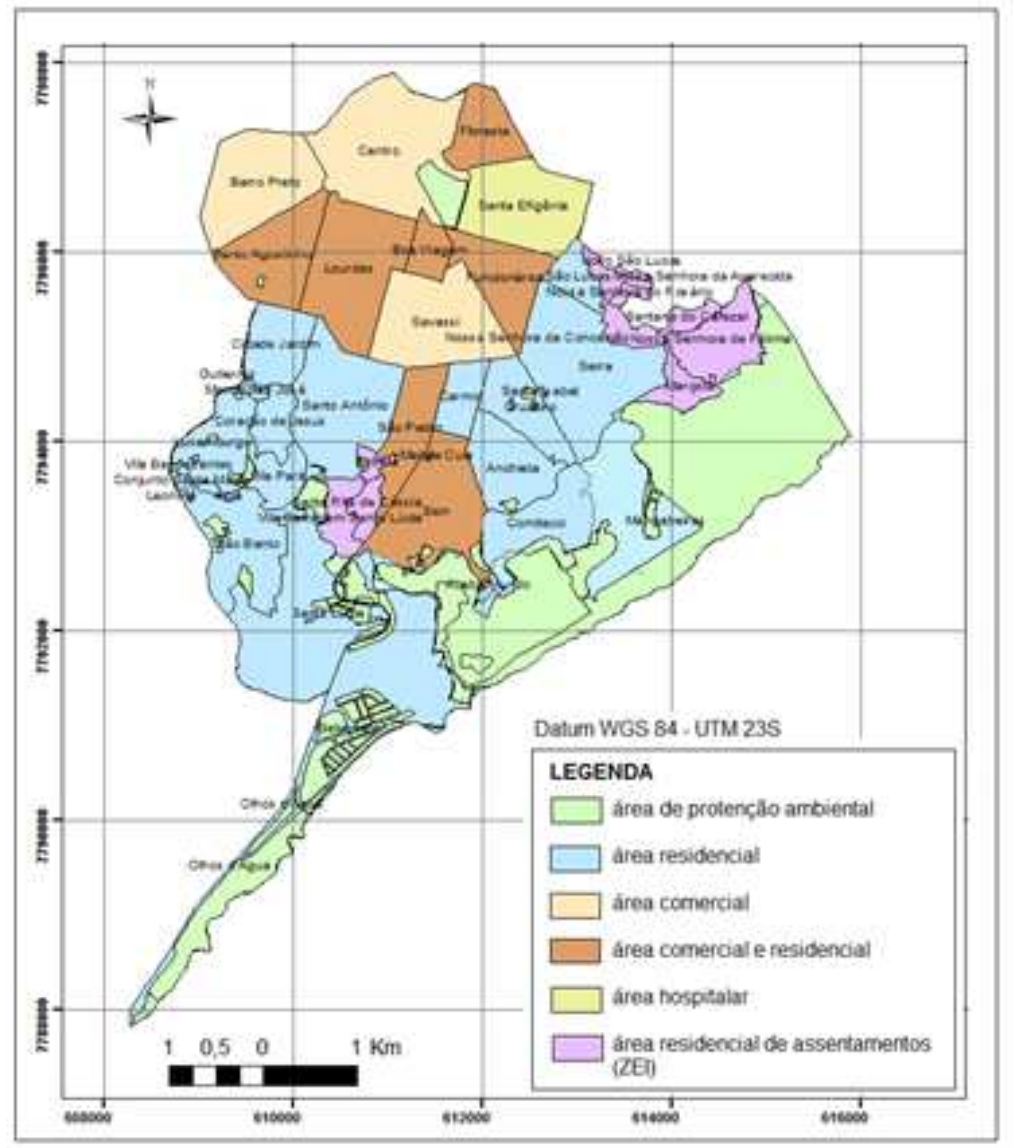

Figura 2 - Ocupação do solo por atividade econômica na Regional Centro-Sul de Belo Horizonte / Fonte: próprios autores 
Para a regional Centro-Sul, convergem de forma pendular, os fluxos de pessoas e mercadorias da Região Metropolitana de Belo Horizonte, assim como aponta o do Plano de Mobilidade Sustentável de Belo Horizonte (Belo Horizonte, 2014). Apesar do predomínio do comércio e serviços, também há bairros residenciais e mistos.

Outro bairro, com características peculiares na regional, é o bairro Santa Efigênia, que se destaca como polo dos serviços de saúde de toda RMBH. Ao sul da regional também são encontradas algumas áreas depreservação ambiental. A regional Centro-Sul não detém áreas de caráter industrial.

\section{- Caracterização Demográfica e Socioeconômica}

Enquanto a PBH divide as regionais em Unidades de Planejamento para facilitar a gestão, o Instituto Brasileiro de Geografia e Estatística (IBGE), as divide em Áreas de Ponderação - AP - para facilitar a realização dos censos demográficos. Ao total, a regional Centro-Sul está dividia em 9 AP's. De acordo com o Censo Demográfico de 2010, elaborado pelo órgão, a regional detém cerca de 283.085 pessoas residentes, em 103.166 domicílios (Brasil, 2010)

Dados censitários são extremamente importantes para criar um sistema de coleta de resíduos sólidos (Brasil, 2011). Saber a quantidade de população é importante para determinar a quantidade total média de resíduos gerados diariamente numa área e, com isso, é possível ser mais preciso ao dimensionar aterros, estações de transbordo e sistemas de tratamento. Já dados referentes a quantidade e densidade de domicílios por área podem ser úteis ao traçar as rotas de caminhões coletores. Por fim, dados sobre a renda de uma região auxiliam na caracterização econômica e qualquer alteração no padrão de renda, modifica o padrão de consumo, que está diretamente relacionado ao volume e à composição gravimétrica da massa de resíduos ali gerada.

Os dados de densidade demográfica, densidade domiciliar e densidade de domicílios foram reunidos e podem ser vistos na tabela 1 , que também dispõe de dados socioeconômicos referentes à renda, em reais. Ao cruzar essas informações em um ambiente SIG, como representado nas figuras abaixo, se torna claro que as regiões com menor renda média (Figura 3-A) são aquelas que possuem também a maior densidade demográfica (Figura 3-B), que são as áreas do Aglomerado Serra e Vila Barragem Santa Lúcia. 


\begin{tabular}{|c|c|c|c|c|c|c|}
\hline \multirow{2}{*}{$\begin{array}{l}\text { Área de } \\
\text { Ponderaçã } \\
\text { o (IBGE) }\end{array}$} & \multirow{2}{*}{$\begin{array}{l}\text { Populaçã } \\
\text { o total }\end{array}$} & \multicolumn{3}{|c|}{ Densidade } & \multicolumn{2}{|c|}{ Renda } \\
\hline & & $\begin{array}{l}\text { Domiciliar } \\
\text { (habitantes } \\
\text { / domicilio) }\end{array}$ & $\begin{array}{c}\text { Demográfica } \\
\text { (habitantes / } \\
\mathrm{km}^{2} \text { ) }\end{array}$ & $\begin{array}{c}\text { De domicílios } \\
(\text { domicílios / } \\
\left.\mathrm{km}^{2}\right)\end{array}$ & $\begin{array}{l}\text { Renda Total } \\
\quad(\mathrm{R} \$)\end{array}$ & $\begin{array}{c}\text { Renda Média } \\
\text { (R\$/habitant } \\
\text { e) }\end{array}$ \\
\hline CS1-A & 30981 & 2.31 & 6746.38 & 2920.511 & 79641017.37 & 2570.64 \\
\hline CS1-B & 28786 & 2.52 & 13782.8 & 5469.365 & 169441351.62 & 5886.24 \\
\hline CS1-C & 25174 & 2.39 & 12049.88 & 5041.791 & 147702911.85 & 5867.28 \\
\hline CS2-A & 27329 & 2.73 & 13092.80 & 4795.897 & 103746393.40 & 3796.20 \\
\hline CS2-B & 34795 & 2.83 & 3391.94 & 1198.565 & 180535858.46 & 5188.56 \\
\hline CS2-C & 23576 & 2.69 & 15601.27 & 5799.729 & 117898852.04 & 5000.80 \\
\hline CS3 & 38405 & 3.52 & 20058.14 & 5698.335 & 16998629.29 & 442.62 \\
\hline CS4-A & 43642 & 2.90 & 18263.34 & 6297.703 & 117658227.93 & 2695.99 \\
\hline CS4-B & 31088 & 2.88 & 6685.38 & 2321.313 & 155278606.63 & 4994.81 \\
\hline
\end{tabular}

Tabela 1 - Dados de caracterização demográfica e econômica da população da regional Centro-Sul

/Adaptado de Censo Demográfico do IBGE (BRASIL, 2010)

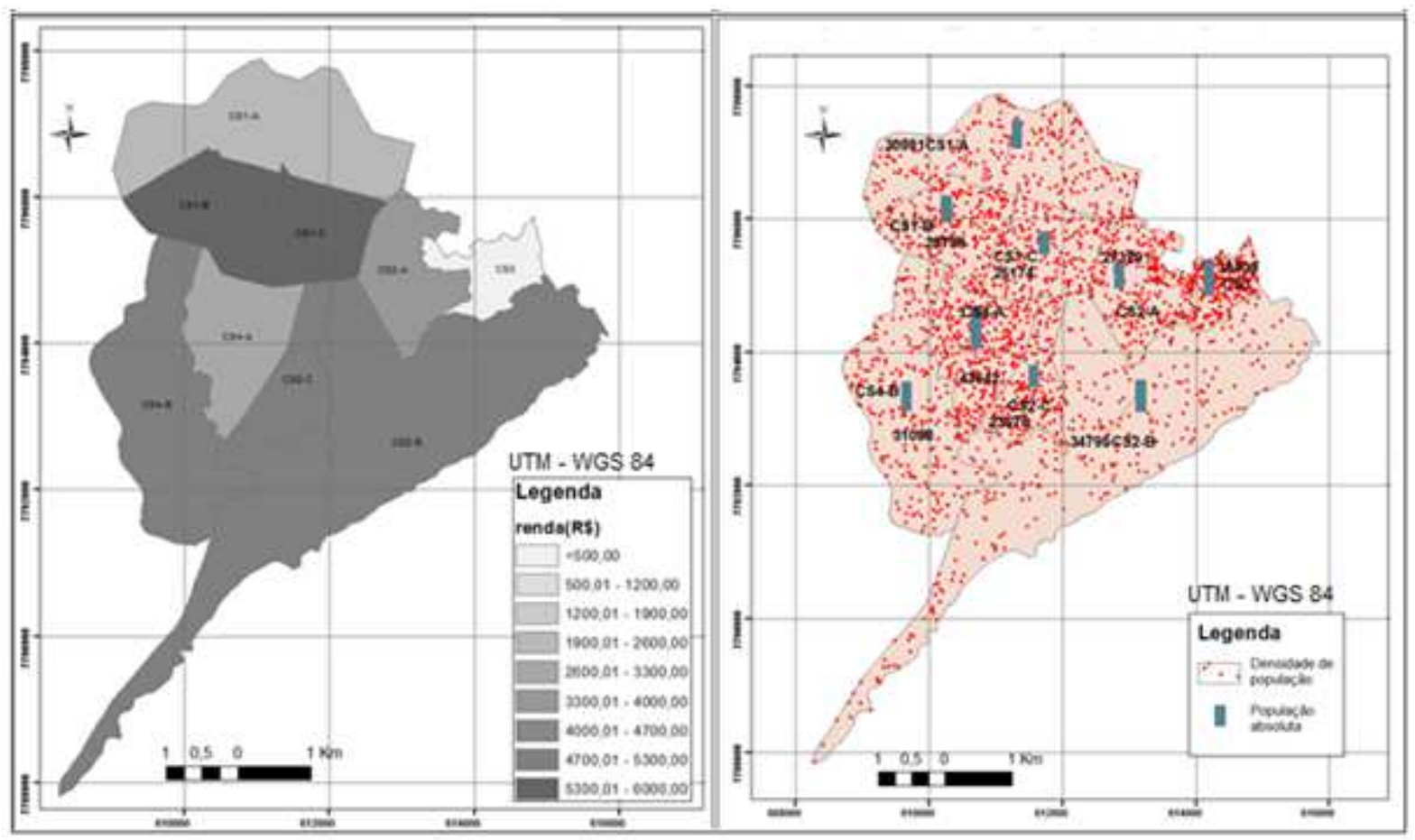

Figura 3 - Renda média (3A), população total e densidade de população por área de ponderação (3) da Regional Centro-Sul/ Fonte: Elaboração dos autores 


\section{- Caracterização Sanitária e dos Serviços de Limpeza Urbana}

Em relação ao saneamento, a Regional Centro-Sul apresenta índices consideravelmente satisfatórios quando comparados à situação nacional. O sistema de abastecimento de água abrange $99.8 \%$ das residências e $99 \%$ delas possuem no mínimo um banheiro interno. Contudo, enquanto a grande maioria dos bairros apresentam percentagens acima de $80 \%$ na coleta de esgotos, há lugares onde esse índice se apresenta na casa dos $70 \%$ de acordo com o Plano Municipal de Saneamento (Belo Horizonte, 2010).

A situação da drenagem urbana, no entanto, é mais preocupante. Belo Horizonte é marcada pelas constantes inundações e alagamentos no verão. Somente na região Centro-Sul a prefeitura registrou 65 ocorrências desses casos entre 2010 e 2014, como afirma o Plano Municipal de Saneamento (2014). A explicação para isso é a soma dos fatos históricos em que a construção da cidade não respeitou a malha hidrográfica natural, aliado ao fato da existência de inúmeras ligações clandestinas de esgoto e deposição ilegal de lixo nos sistemas coletores. Na tentativa de resolver o problema a prefeitura desenvolveu ações estruturais na região como as obras de recuperação da Barragem Santa Lúcia e a recuperação de Nascentes no Aglomerado Serra. Ações não estruturais também são desenvolvidas constantemente como programas de educação sanitária em centros de saúde pública e a limpeza de córregos e de bocas-de-lobo (Belo Horizonte, 2010).

Conforme aferido em entrevista com os funcionários da superintendência de limpeza, a deposição ilegal de resíduos também ocorre em lotes vagos, principalmente os de domínio público localizados em bairros de classes média e baixa. A limpeza de alguns desses lotes, bem como a limpeza de córregos e bueiros é um serviço oferecido pela SLU, porém de forma terceirizada. Infelizmente, a prefeitura não conhece o número total de lotes baldios no município, muito menos conhece todos aqueles terrenos que foram transformados em bota-foras e, por consequência, também desconhece a quantidade de lixo armazenada nesses espaços. Desses locais, na região Centro-Sul, os poucos conhecidos e que são higienizados contribuíram, em 2014 , com $11.078 \mathrm{~kg}$ de resíduos para o sistema de coleta, de acordo com o relatório técnico divulgado pela SLU em 2015.

Esses terrenos se tornam também um elemento gerador de altos impactos ambientais uma vez que o lixo ali depositado contribui para a contaminação de corpos d'água, assoreamento, enchentes, proliferação de vetores transmissores de doenças (Mucellin, 2007). Os impactos são tão preocupantes, que em 2007, o Plano Diretor de Desenvolvimento Integrado - PDDI, realizado pela Região Metropolitana de Belo Horizonte - RMBH, levantou a taxa de lotes vagos em toda sua jurisdição. O PDDI também apresentou 
propostas para a gestão integrada de diversos temas, entre eles a gestão territorial e a gestão de resíduos sólidos (Minas Gerais, 2011).

Ainda segundo os funcionários da SLU, os serviços oferecidos pela superintendência municipal são em quase sua totalidade terceirizados por meio de editais de licitação. 0 último contrato para a região, referente ao biênio 2014-2015 foi estimado em cerca de 2.9 milhões de reais, segundo a SLU em 2014. Somente dois serviços não são contemplados nessa terceirização: coleta, transporte e disposição dos resíduos hospitalares e parte da varrição de vias e espaços públicos.

De acordo com a Política Nacional de Resíduos Sólidos (2010), a responsabilidade da destinação final dos resíduos de saúde é obrigação exclusiva de seus geradores, isso faz com que a SLU assuma a responsabilidade sobre os resíduos gerados em hospitais, postos de saúde, farmácias e centros comunitários de jurisdição municipal. De acordo com os últimos relatórios dos serviços de limpeza foram coletadas, em 2014, 8.538,74 toneladas de resíduos do serviços de saúde na regional Centro-Sul, uma parcela correspondente a $92 \%$ do total do município e cujo peso se deve à região hospitalar do bairro Santa Efigênia. Atualmente esses resíduos são aterrados na última célula disponível do aterro sanitário da Central de Triagem de Resíduos da BR-040.

A tarefa de varrição promove atividades para ajuntar, acondicionar e remover os resíduos lançados nos logradouros pela ação humana ou por causas naturais. De acordo com o Plano Municipal de Saneamento (2014), o serviço se dá de forma manual ou mecanizada englobando sarjetas, calçadas e áreas públicas em aproximadamente $95 \%$ da extensão das vias urbanas pavimentadas. A frequência da limpeza é de no mínimo duas vezes por semana, chegando a ser diária em algumas áreas como a zona hipercentral, que é parte da região Centro-Sul, conforme relatado por Assis (2012).

Apesar de uma frequência alta, ainda é possível ver dejetos e poeira nas ruas e avenidas do Centro. A atividade de varrição encontra nessa área um complicado entrave: intensos, ás vezes caóticos, fluxos de pessoas e veículos provenientes de toda região metropolitana. Esses fluxos além de trazerem consigo grandes volumes de resíduos, o que torna necessário uma elevada frequência de limpeza, ainda comprometem a segurança dos trabalhadores do sistema.

Enquanto a varrição manual é realizada diretamente pela SLU, a varrição mecânica é terceirizada, bem como a coleta, transporte e disposição final adequada de resíduos domiciliares, do comércio e da construção civil além do transporte dos materiais recicláveis e da manutenção dos equipamentos de limpeza. Isso faz com que uma única empresa seja 
responsável por uma gama de serviços muito grande e necessite de um sólido sistema de gestão.

A complexidade da região reafirma esse preceito, uma vez que dentro da regional existem quatro sistemas de coleta diferentes: o sistema porta a porta convencional; o sistema de coleta seletiva porta a porta, parcialmente em alguns bairros, apenas para recicláveis (papel, metal, plástico e vidro); o sistema de entrega voluntária em alguns dos bairros e o sistema especial em áreas de vilas e aglomerados. Ao total, 93.72\% das residências da região são atendidas por algum deles. Apesar disso há uma grande disparidade espacial, enquanto há bairros com $100 \%$ de residências atendidas, existem outros com somente $40 \%$ de atendimento, de acordo com a SLU (2015) . Observa-se que quando esses dados são cruzados com as estimativas socioeconômicos apontam para maiores deficits nas regiões mais frágeis socialmente, como a Vila Barragem Santa Lúcia e o bairro Santana do Cafezal, o que ressalta ainda mais essa disparidade.

Paradoxalmente, os bairros nobres do Santo Agostinho e do Lourdes apresentam uma coleta do tipo porta a porta abaixo da média. Essa consequência se deve há outra causa: a zona possui um tráfego condensado em um sistema de trânsito constituído por muitas vias de mão única, o que torna o traçado das rotas dos caminhões para atingir todos os edifícios algo muito complexo. Apesar disso, a área é contemplada com o sistema de entrega voluntária, possui equipamentos para a coleta seletiva e aqueles edifícios que não recebem o serviço porta a porta não estão localizados muito distantes das rotas dos caminhões coletores. Sendo assim, mesmo estando abaixo da média regional, esses bairros possuem um sistema considerado eficiente pela SLU.

A coleta porta a porta convencional de resíduos é efetuada prioritariamente por caminhões coletores compactadores, acompanhados por guarnição composta de um motorista e quatro coletores. Ao total rodam 141 veículos em 246 itinerários de coleta, com frequência diária ou em dias alternados, e sempre no período noturno. Os caminhões da coleta convencional são encaminhados para a estação de transbordo, localizada na CTR da rodovia BR-040. Ali, os residuos são triados, acondicionados em caminhões maiores e, posteriormente, levados para o aterro de Macaúbas, no município de Sabará, na região metropolitana (Assis, 2012).

A coleta seletiva é realizada em caminhão baú, caminhão compactador ou veículo utilitário. Os residuos da coleta seletiva são encaminhados às cooperativas cadastradas pela prefeitura. Silva (2008) demonstrou que a regional é a que detem o maior potencial percentual de produção de recicláveis na cidade. Contudo, Assis (2012) afirma que esse potencial não é aproveitado, uma vez que correspode a no máximo 0,5\% do total de 
resíduos produzidos. Parreira (2010), por sua vez, reafirma a necessidade de ampliar o serviço, que não gera o mesmo passivo ambiental da deposição dos resíduos em aterros, permite economizar energia e matérias primas não renováveis e ainda contribui com a geração de empregos e a inclusão social de muitos trabalhadores.

Uma parte dos materiais recicláveis é recolhida porta a porta, enquanto outra é coletada nos chamados Locais de Entrega Voluntária - LEV's que são mostradas na figura 4. As LEV's também têm capacidade para recolher pilhas e baterias, contudo são subutilizadas. A regional Centro-Sul dispunha de 21 pontos até 2010, quando a prefeitura decidiu fechar alguns desses pontos devido à depredação, má utilização dos contêineres ou reivindicações de moradores ou comerciantes que alegavam a incompatibilidade do equipamento com o meio urbano. Até o início de 2016, a Região contava apenas com 11 pontos. Todas elas recolhem vidro, mas somente uma está habilitada para receber plástico, metal e papel.

O mau uso dos contêineres ocorre quando há mistura de materiais ou deposição de matérias não recicláveis contaminando os recicláveis, o que reflete desconhecimento da população sobre a função dos equipamentos. As depredações de LEV's e lixeiras são puros atos de vandalismo e constituem um dos maiores problemas da regional Centro-Sul. De acordo os gestores da SLU, o grande empecilho para que se aumentem os serviços de coleta seletiva é encontrar locais que recebam e tratem esses materiais. Atualmente, os materiais coletados nas LEV's e pela coleta seletiva porta a porta são encaminhados para duas cooperativas de catadores: a ASMARE - Associação dos Catadores de Papel, Papelão e Material Reaproveitável e a ASSOCIRECICLE - Associação dos Recicladores de Belo Horizonte. Devido a questões econômicas, políticas e gerenciais, as duas cooperativas que atuam em parceria com a SLU não conseguem aumentar suas capacidades de tratamento. As mesmas dificuldades também impedem a SLU de fechar parcerias com outras entidades

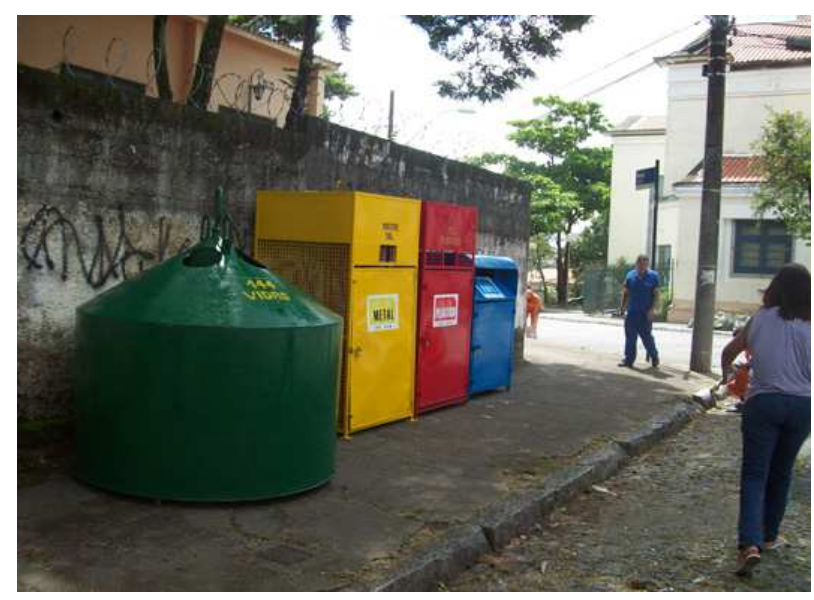

Figura 4 - Local de Entrega Voluntária na regional Centro-sul, de Belo Horizonte-MG Fonte: SLU de Belo Horizonte 
Outro equipamento de limpeza urbana utilizado no sistema de coleta por entrega voluntária é a Unidade de Recebimento de Pequenos Volumes - URPV. É um local dotado de baias ou caçambas em que a prefeitura recebe materiais como pneus inservíveis, resíduos da construção civil, podas de árvores, lâmpadas, eletrônicos e outros materiais que serão encaminhados para a correta destinação final ou recuperação. A região Centro-Sul conta com apenas duas URPV's, que recolhem cerca de 6.200 toneladas de resíduos por ano, de acordo com a SLU(2015).Apenas duas URPV's para atender uma região tão extensa não é o bastante para atender a demanda pelo serviço e o reflexo disso é o surgimento de "botaforas", locais clandestinos de disposição de resíduos, em áreas onde esses equipamentos não estão presentes. A prefeitura alega que para a implantação de mais URPV's necessita de terrenos e estes são escassos em uma região tão urbanizada. Tal fato é questionável uma vez que a própria SLU é responsável pela limpeza de 78 áreas públicas e 33 lotes particulares transformados em bota-foras, de acordo com o próprio Plano Municipal de Saneamento de 2014.

Ligado às URPVs, existe o Programa "Carroceiros", que autoriza pessoas em carroças, tracionadas por cavalos ou burros, a transportarem resíduos de residências ou comércio até as URPVs. Criado na década de 90, o Programa foi uma tentativa de diminuir as disposições clandestinas, em grande parte, feitas pelos próprios carroceiros e inserí-los como agentes participantes da Limpeza da cidades. Esse Programa é muito polêmico na cidade, especialmente, pelas denúncias de maltrato aos animais.

Os agentes da superintendência de limpeza urbana relatam que os as URPVs apesar de serem equipamentos que possuem um grande contribuição na destinação de resíduos de construção civil, podas e outros, há em geral, uma inaceitabilidade pela população. Os equipamentos, muitas vezes, não são bem vistos e não compõe adequadamente o ambiente urbano. Muitos populares também se incomodam com a presença dos cavalos dos carroceiros, reclamam da poluição visual, mal cheiro e surgimento de roedores, que são atraídos quando os resíduos não são bem acondicionados e estão contaminados com material orgânico.

Já a coleta domiciliar em vilas e favelas, devido às difíceis condições de acesso e tráfego dos veículos, impostas por essa realidade, têm representado desafios ao poder público para prestação regular do serviço de limpeza urbana. A coleta domiciliar porta a porta nessas regiões também é efetuada com caminhões compactadores, de tamanho convencional ou reduzido, nas vias que apresentam condições para o tráfego. Em alguns becos, devido às 
condições de largura e declividade, a coleta é feita com carrinhos de mão conduzidos pelos chamados "agentes comunitários de limpeza urbana" - ACLU's (Belo Horizonte, 2014).

Esses trabalhadores são pessoas da própria comunidade contratadas e instruídas pela SLU em parceria com os centros de saúde da região. Eles realizam a coleta no período diurno, diariamente ou três vezes por semana em dias alternados (Belo Horizonte, 2014). O programa que os abrange cumpre uma função de inclusão social e leva empregos a zonas extremamente frágeis, porém apresenta falhas uma vez que conceitos como a coleta seletiva não são efetivamente trabalhados.

Quanto à composição gravimétrica dos resíduos, a última realizada para o município em 2007 e apresentada no Plano Municipal de Saneamento de 2014, registrou que os resíduos da regional Centro-Sul são compostos em média por $57 \%$ de material orgânico. A explicação para o fato, está na presença dos grandes mercados, feiras e hortifrutigranjeiros, além da incontável quantidade de estabelecimentos como restaurantes, bares e lanchonetes que servem o centro comercial da cidade. Esses resíduos geralmente são encaminhados ao aterro Macaúbas como lixo comum, desprezando seu potencial de reciclagem. O programa de compostagem existente na cidade não consegue reciclar nem 1 \% dos resíduos orgânicos gerados como apresentou Silva (2008), além do que, a unidade de compostagem, localizada na CTR BR-040, trabalha 50\% abaixo da sua capacidade segundo os funcionários da SLU. O programa recolhe resíduos orgânicos de aproximadamente 40 estabelecimentos comerciais e feiras, cadastrados pela prefeitura.

\subsection{Avaliação S.W.O.T.}

Após a realização do diagnóstico territorial, socioeconômico e dos serviços de limpeza urbana, foi realizada, a partir da tabela 2, a análise das forças, fraquezas, oportunidades e ameaças (SWOT) existentes em relação ao sistema de gestão de resíduos sólidos da região Centro-Sul. A análise constitui uma síntese da caracterização feita e pode auxiliar na formulação de propostas estratégicas e na otimização da capacidade do sistema de gerenciamento de resíduos urbanos.

Tanto a análise SWOT, quanto o georeferenciamento tem sido propostos como ferramentas válidas na tomada de decisão na gestão de resíduos. Alguns exemplos de suas diversas utilizações são: análise sobre a inserção das cooperativas na gestão de resíduos sólidos de Bogotá (Martínez; Piña, 2015); a elaboração do Plano Municipal de Gestão de Resíduos de Lisboa (Lisboa, 2016); estratégicas para integração da gestão ambiental na região metropolitana de Tehran (Pourkarimi, et al., 2016); uso de SIG no gerenciamento de 
resíduos sólidos (Marriapan e Selvi, 2015; Gallardo et al., 2014; Ornelas, 2011); SIG no monitoramento da distribuição de resíduos de construção civil e identificação de áreas para destinação e reciclagem (Wu et al., 2015).

\begin{tabular}{|c|c|c|}
\hline & Internos & Externos \\
\hline \multirow[b]{2}{*}{ 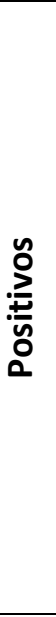 } & Forças (S) & Oportunidades (0) \\
\hline & $\begin{array}{l}\text { - Força política e comercial polarizadoras sobre } \\
\text { o Estado de Minas Gerais } \\
\text { - 95\% da extensão de vias recebe serviço de } \\
\text { varrição semanalmente } \\
\text { - Existência de programa de reciclagem porta a } \\
\text { porta } \\
\text { - Existência de programa de compostagem } \\
\text { Programas de limpeza urbana com inclusão } \\
\text { social e geração de postos de trabalho dentro } \\
\text { de comunidades frágeis } \\
\text { - Áreas com } 100 \% \text { de domicílios atendidos com } \\
\text { algum tipo de coleta }\end{array}$ & $\begin{array}{l}\text { - PDDI da RMBH apresenta propostas e } \\
\text { possui banco de dados que podem ser } \\
\text { aproveitados } \\
\text { - Reciclagem pode ser mais explorada } \\
\text { economicamente }\end{array}$ \\
\hline \multirow[b]{2}{*}{ 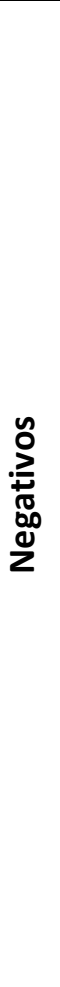 } & Fraquezas (W) & Ameaças (T) \\
\hline & $\begin{array}{l}\text { - Regiões mais frágeis socialmente apresentam } \\
\text { as maiores demandas de saneamento básico } \\
\text { - Topografia e composição irregular das vias } \\
\text { dificultam o recolhimento de resíduos em vilas } \\
\text { e aglomerados } \\
\text { - Prefeitura e SLU não possuem dados exatos } \\
\text { sobre os locais de deposição clandestina } \\
\text { - A grande maioria dos resíduos são aterrados } \\
\text { desprezando seu potencial de } \\
\text { reaproveitamento } \\
\text { - Equipamentos de limpeza urbana, às vezes, } \\
\text { não se integram ao meio urbano e, por isso, não } \\
\text { são aceitos pela população } \\
\text { - LEV's e URPV's subutilizadas ou escassas } \\
\text { - Programa de compostagem é restrito frente a } \\
\text { enorme quantidade de matéria orgânica gerada } \\
\text { - Dependência de áreas externas particulares } \\
\text { para aterragem, como o aterro Macaúbas em } \\
\text { Sabará }\end{array}$ & $\begin{array}{l}\text { - Intenso fluxo pendular de pessoas } \\
\text { vindas de outras regionais e outras } \\
\text { cidades. } \\
\text { - Sistema de drenagem é comprometido } \\
\text { pela deposição clandestina de lixo } \\
\text { - Deposição clandestina de lixo em lotes } \\
\text { vagos } \\
\text { - Células de aterragem dos resíduos } \\
\text { hospitalares estão se esgotando, o que } \\
\text { confere um problema para todo o } \\
\text { município } \\
\text { - Alto trafego de veículos dificulta a } \\
\text { varrição de vias públicas } \\
\text { - Desconhecimento da população sobre } \\
\text { a correta forma de uso dos } \\
\text { equipamentos de limpeza urbana como } \\
\text { LEV's e URPV's } \\
\text { - Depredação e vandalismo dos } \\
\text { equipamentos }\end{array}$ \\
\hline
\end{tabular}

Tabela 2 - Relação das Forças, Oportunidades, Fraquezas e Ameaças (SWOT) do sistema de gestão de resíduos sólidos da regional Centro-Sul, de Belo Horizonte-MG

Através da análise SWOT e do memorial cartográfico pode-se reunir as diversas informações disponíveis a respeito da gestão de resíduos sólidos na regional Centro-Sul, permitindo um 
exame das forças e fraquezas internas do sistema, bem como suas oportunidades de crescimento e as ameaças externas que podem interferir. Com base nessa análise, foram propostas algumas estratégias para maximizar os pontos fortes e as oportunidades, minimizando as deficiências, causadas pelas fraquezas, e os impactos, que podem ser causados pelas ameaças.

\section{Forças}

Por ser um polo comercial e de serviços, a regional Centro-Sul pode vir a ser um núcleo impulsionador de novas propostas para otimizar a gestão de resíduos na cidade. O setor comercial e de serviços sempre tem um poder político significativo de maneira formal (legislativo) e informal nas cidades, especialmente por movimentar a economia local. Além disso, outra característica importante, é o fluxo de pessoas muito acima do que ocorre em outras regionais. Obviamente, a geração de resíduos é impactada, mas ao mesmo tempo, programas e campanhas educativas ali desenvolvidas podem influenciar os trabalhadores e transeuntes e, consequentemente, repercutir em outras localidades..

Como os sistemas de coleta são abrangentes e já bem estabelecidos, é possíveldetectar mais facilmente os gargalos existentes em comparação a outras regionais. Os programas de coleta seletiva, onde existentes, tem boa aceitação pela população, inclusive, sua expansão é pleiteada pela população.

\section{Fraquezas}

No entanto, as áreas de maior fragilidade econômica e social, associados aos problemas de infra-estrutura e de segurança, é uma das fraquezas identificadas na regional. Programas específicos de limpeza urbana não podem estar desvinculado das demais melhorias que precisam ser implantadas nessas áreas, o que demanda tempo e, especialmente, políticas públicas específicas a fim de diminuir as desigualdades internas. Outras fraquezas detectadas estão relacionadas às problemas do sistema de gestão de resíduos do município como o todo, ou seja, afeta todas as demais regionais, como a falta de dados sobre a composição e do quantitativo gerado, em épocas do ano e por geradores específicos (domicílios, comércio, equipamento públicos etc); a precariedade dos equipamentos públicos existentes (LEV's e URPV's) e falta de informação e sensibilização sobre suas funções e, a crescente geração de resíduos na cidade anualmente.

\section{Oportunidades}

As oportunidades são inúmeras a longo prazo, desde que as fraquezas e ameaças sejam sanadas. Em relação as duas das fraquezas apontadas: LEV's e URPV's subutilizadas ou 
escassas e, ás vezes, que não se integram ao meio urbano de forma aceitável pela população, é proposto, através das ferramentas de cartografia, o planejamento da instalação de novas unidades em pontos estratégicos da região, com massiva campanha de sensibilização.

LEV's devem existir em todos os bairros, preferencialmente nos centros comerciais, encurtando a distância de deslocamento para todas as pessoas. Sugere-se que as LEV's fechadas devem ser reabertas e todas elas devem estar habilitadas para receber vários tipos de materiais e não somente vidro, como é atualmente. Novas URPV's devem ser localizadas próximas a bairros que tenham maiores demandas pelo recolhimento de resíduos coletados por elas, como é o caso do Aglomerado da Serra. Outra constatação foi que as LEV's não apresentam nenhuma informação de como utilizá-los corretamente. Logo, uma medida simples, que pode ser eficiente para informar a população, que utiliza os equipamentos, é dispor cartazes com instruções de uso em cada contêiner. Segundo o Plano Diretor de Belo Horizonte (1996), um das diretrizes relativas ao meio ambiente é "gerenciar e tratar os resíduos sólidos gerados pelo Município, promovendo, inclusive, campanhas educativas e políticas públicas que visem a contribuir com o reaproveitamento, a redução, a reutilização e a reciclagem destes resíduos." Os programas de educação ambiental são imprescindíveis para melhorar a eficiência de sistemas de gestão de resíduos. As cidades de Milão e Ljubljana, são exemplos dos resultados positivos de campanhas educativas em diversas mídias e diferentes modos de abordagem da população (Vismara,2016; Gregoric, 2016).

Também num cenário mais próximo, é possível associar as políticas municipais às metropolitanas, especialmente pelo movimento de pessoas entre a regional Centro-Sul e os demais municípios da RMBH, como também salienta Assis (2012). Desta forma, atendendo o Plano Diretor de 1996, que especifica as diretrizes relativas à limpeza urbana: promover a articulação do Município com a região metropolitana no tocante a coleta, transporte, tratamento e destinação final dos resíduos sólidos; implantar programas especiais de coleta e destinação final do lixo em áreas ocupadas por população de baixa renda.

As cooperativas de reciclagem quando bem estruturadas, com infraestrutura moderna, organização como microempresa, cumprimento da legislação trabalhista e assessoria técnica, são oportunidades de geração de trabalho e renda, especialmente, possibilitando maior inclusão dos trabalhadores da reciclagem (catadores). A ampliação da compostagem e/ou biometanização, por sua vez, podem desviar grande parte dos resíduos orgânicos que são encaminhados ao aterro sanitário. Igualmente, são oportunidades de trabalho e renda, além da redução das externalidades ambientais causadas pela má destinação desses resíduos. Ademais, uma das diretrizes do Plano Diretor de Belo Horizonte é: o incentivo à 
industria de reciclagem, reaproveitamento e reutilização de resíduos sólidos (Belo Horizonte, 1996).

\section{Ameaças}

Pode-se resumir as ameaças, como sendo a manutenção da situação vigente na regional e em todo o restante da cidade. Com a geração de resíduos per capita ascendendo e o sistema não se atualizando, o que atualmente compromete as melhorias e num futuro próximo poderá agravar ainda mais a situação dos resíduos. Não se pode deixar de considerar que, por trás dessas ameaças, muitas vezes estão as questões políticas, que interferem na gestão dos municípios. As mudanças políticas e de estratégias que ocorrem a cada novo grupo político que assume o poder, às vezes leva a desconsider investimentos e programas positivos em que seus antecessores investiram e, assim, é emperrada a continuidade de boas práticas de gestão. Uma estratégia importante que poderá auxiliar nesse aspecto, é a aprovação do Plano Municipal de Resíduos Sólidos, em elaboração no período de 2014-2016. Desta forma, os gestores conhecerão os objetivos e metas traçados coletivamente e que expressam o pensamento da população em geral, sobre como a gestão de resíduos deve ser conduzida na cidade; por outro lado, os cidadãos poderão fiscalizar melhor as ações do governo local.

\section{Considerações Finais}

Toda a metodologia de diagnóstico e análise empregada deixa claro que a gestão dos resíduos sólidos na região Centro-Sul é um grande desafio. O ordenamento territorial da região deve atender as pessoas que ali residem e, ao mesmo tempo, compatibilizar fluxos e demandas de grande parte do Estado de Minas Gerais. Esta tarefa se torna ainda mais difícil quando a região assume essas demandas externas, mas pouco compartilha as soluções dos problemas com outras áreas.

Qualquer alternativa técnica proposta para o sistema deve ser permeada por um viés de integração da região com outras regionais do município, outras cidades da região metropolitana e com a participação mais intensa dos três níveis de governo. Cabe também

à prefeitura e à SLU aproveitar as oportunidades de integração. A Agência de Desenvolvimento da Região Metropolitana, através do PDDI, estimula metas, sugere 
alternativas e oferece subsídios para que os municípios trabalhem de forma integrada os problemas relacionados aos resíduos sólidos.

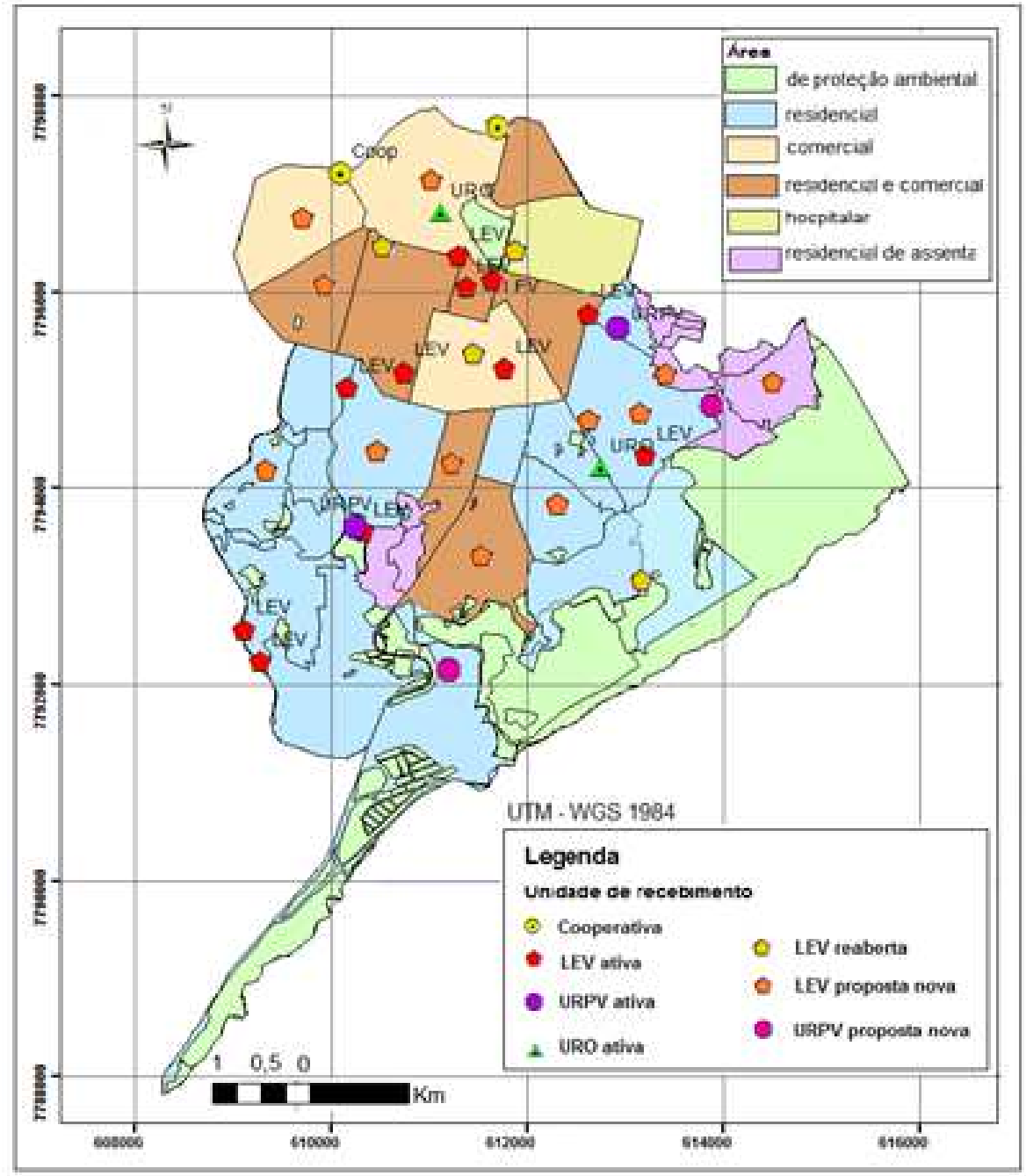

Figura 5 - Locais de Entrega Voluntária existentes, Unidades de Recebimento de Pequenos Volumes cooperativas de reciclagem e novos pontos a serem instalados na Região Centro-Sul

$\backslash$ Fonte: Elaborado pelos autores

Essa oportunidade pode resolver grande parte das ameaças. Observa-se que uma parte considerável da sujeira das vias e da subutilização, e mesmo depredação, das lixeiras é promovida por pessoas não residentes na Centro-Sul. Pode-se criar ações educativas especificamente para elas, obviamente, os programas de educação ambiental, devem ocorrer em toda a cidade e de forma continuada. Para viabilizar as campanhas é proposto que a SLU trabalhe em parcerias com mais escolas, igrejas, centros de saúde, centros 
comunitários, além da abordagem porta a porta em domicílios e estabelecimentos comerciais.

Ainda sobre esses equipamentos, duas fraquezas são apontadas: LEV's e URPV's subutilizadas ou escassas e, ás vezes, não se integram ao meio urbano de forma aceitável pela população. A fim, de minimizar a primeira a cartografia possibilitou o planejamento da instalação de novas unidades pontos estratégicos da região. LEV's devem existir em todos os bairros, preferencialmente nos centros deles, encurtando a distância de deslocamento para todas as pessoas. Muitas das LEV's fechadas devem ser reabertas pois ainda são consideradas uteis e todas elas devem estar habilitadas para receber vários tipos de materiais e não somente vidro como é atualmente. Novas URPV's são previstas próximas a bairros que tenham maiores demandas pelo recolhimento de resíduos coletados por elas, como é o caso do Aglomerado da Serra. A figura 5 traz um mapa que compara entre a situação atual desses equipamentos e os novos sugeridos. Outra constatação foi que as LEV's não apresentam nenhuma informação de como utilizar corretamente os reservatórios. Logo, uma medida simples que pode ser eficiente para informar a população que utiliza os equipamentos é dispor carteis com instruções de uso em cada baia.

Quanto a inaceitabilidade da população é proposto buscar alternativas para o design dos equipamentos. Eles devem possuir um desenho moderno, que permita a composição paisagística e, ao mesmo tempo, sejam tecnicamente úteis, economicamente viáveis e socialmente atraentes e higiênicos. Esta última característica é essencial, pois é a partir do momento em que a população se apropria adequadamente do equipamento urbano, que ele pode ser utilizado da melhor maneira possível.

Um dos principais problemas para aumentar a rede de coleta de recicláveis em Belo Horizonte é a falta de locais com infra-estrutura adequada para a destinação desses materiais. Logo, antes de se propor aumentar a prática da reciclagem, a SLU deve firmar parcerias com outras cooperativas, ou mesmo empresas do setor, que aceitem receber esses materiais.A coleta seletiva porta a porta é implementada em somente em alguns bairros, porém ela pode ser implantada em mais locais com algumas adaptações, como nas áreas de aglomerados onde existem os ACLU's. Nesses locais, a SLU pode instruir a população a separar o lixo em três categorias simples: lixo de banheiro para ser aterrado, 
lixo orgânico para ser compostado e resíduos inorgânicos secos para serem reciclados. Os agentes, então, devem receber instruções para acondicionar adequadamente esses materiais em seus carrinhos a fim de evitar a contaminação. E por fim, dar a cada categoria, o destino adequado.

Quanto aos problemas da varrição é proposto aumentar o percentual do serviço mecanizado e realizar fora do horário de pico de trafego para garantir a eficiência e a segurança dos funcionários. Para o desconhecimento dos locais de bota-foras, cabe a SLU levantar esses dados e formular uma cartografia que permita fiscalização e a higienização desses locais que podem ser, inclusive, fontes de vetores de doenças como dengue e leptospirose.

Quanto aos problemas de esgotamento do aterro da rodovia BR040 para receber resíduos hospitalares e material orgânico outra vez a solução pode ser a integração com outras jurisdições. Vale lembrar que os serviços de saúde e alimentação oferecidos na região são utilizados por pessoas de todo o Estado. Os resíduos de saúde necessitam de uma solução mais rápida e a proposta aqui sugerida é buscar fundos para implantar um sistema de incineração, solução tecnológica mais adequada atualmente para sua destinação final.

Já a alternativa para os resíduos orgânicos é aumentar o sistema de compostagem que obtém resultados satisfatórios. Se prevê o aumento do sistema de recolhimento que, por hora, abrange apenas os grandes geradores e não atende os pequenos e médios. Contudo, para isso, é necessário buscar novas áreas, que não necessariamente existem em Belo Horizonte.

\section{Referências bibliográficas}

AGÊNCIA DE DESENVOLVIMENTO DA REGIÂO METROPOLITANA DE BELO HORIZONTE. Plano Diretor de Desenvolvimento Integrado da Região Metropolitana de Belo Horizonte: Propostas de Políticas Setoriais, Projetos e Investimentos Prioritários. 1ạ ed. Belo Horizonte, Brasil: Governo do Estado de Minas Gerais, 2011. ASSIS, Camila Moreira de. Avaliação da gestão integrada de resíduos sólidos urbanos em municípios da região metropolitana de Belo Horizonte. Belo Horizonte: Escola de Engenharia; Universidade Federal de Minas Gerais, 2012. 404 p. Tese de Doutorado em Saneamento, Meio Ambiente e Recursos Hidrícos.

ASSOCIAÇÃO CULTURAL DO ARQUIVO PÚBLICO DA CIDADE DE BELO HORIZONTE. História dos Bairros: Regional Centro-Sul [Em linha]. 1ạ ed. Belo Horizonte, Brasil: ACAP-BH, 2008. 80 pp. [Consultado em 13 outubro 2015]. Disponível em: www.pbh.gov.br/cultura/arquivo 
BALDIM, R. Diplomacia de Cidades: Agendas Globais, Acordos Locais. In: Geopolítica das cidades: velhos desafios, novos problemas. Brasília: IPEA, 2016. 372 p.

BELO HORIZONTE. LEI № 7.165, DE 27 DE AGOSTO DE 1996. Institui o Plano Diretor do Município de Belo Horizonte. Diário Oficial de Belo Horizonte, agosto de 1996.

BELO HORIZONTE. Governo Municipal de Belo Horizonte. [Em linha]. Lei Municipal no 7166, de 27 de agosto de 1996 que dispõe sobre o Parcelamento, Uso e Ocupação do Solo. Estabelece normas e condições para parcelamento, ocupação e uso do solo urbano no município. [Consulta em 20 outubro de 2015]. Disponível em: http://portalpbh.pbh.gov.br/pbh/ecp/comunidade.do?evento=portlet\&app=regulacaourbana\&pg=5570\&tax= $\underline{20542}$

BHTRANS. Plano Diretor de Mobilidade Urbana de Belo Horizonte. [Em linha]. Belo Horizonte, Brasil: Empresa de Transporte Público de Belo Horizonte, 2014. [10 de Setembro de 2015]. Disponível em: http://www.bhtrans.pbh.gov.br/portal/pls/portal/!PORTAL.wwpob page.show? docname=9610266.PDF

BRASIL, Casa Civil da Presidência da República. Lei no 12.305-Institui a Política Nacional de Resíduos Sólidos; altera a Lei no 9.605, de 12 de fevereiro de 1998; e dá outras providências. [Em linha]. Brasília, Brasil: Diário Oficial da República Federativa do Brasil, 02 de agosto de 2010. [Acesso em 12 de novembro de 2015]. Disponível em: https://www.planalto.gov.br/ccivil_03/_ato2007-2010/2010/lei/l12305.htm

CERVO, A.L. e BERVIAN, P.A.. Metodologia Científica. 5aed.. São Paulo : Prentice Hall. 2002. ISBN-10: $858791815 \mathrm{X}$

EUROPE IN THE MEDITERRANEAN (MED). Low Cost Zero Waste Municipality. Zero Waste Project, 2009 [viewed 20 November 2015]. Available from: http://www.med-zerowaste.eu/partnership.html

GALLARDO, A., et al. Methodology to design a municipal solid waste generation and composition map: A case study. Waste Management, November 2014, vol. 34 no 11 p. 1920-1931. Available from: http://dx.doi.org/10.1016/j.wasman.2014.05.014

GREGORIC, J. On our way to sustainable society, 2016. [viewed 23 october 2016]. Available from: http://www.environnement.brussels/sites/default/files/user files/joze gregoric presentation snaga reuse a nd repair may 2016.pdf

HARISSON, Jeffrey P. Strategic Planning and SWOT Analysis. In: HARRISON, Jeffrey P.. Essentials of Strategic Planning in Healthcare. Chicago, USA : Health Administration Press, 2010. Cap. 5. p. 91-97.

INSTITUTO BRASILEIRO DE GEOgRAFIA E ESTATístiCA. Censo Demográfico. [Em linha]. Brasília, Brasil, 2010. [Consultado em 26 novembro de 2015]. Disponível em: http://www.ibge.gov.br/home/estatistica/populacao/censo2010/default.shtm

INSTITUTO DE PESQUISAS ECONÔMICAS APLICADAS. Relatório de Pesquisa: Pesquisa sobre Pagamento por Serviços Ambientais Urbanos para Gestão de Resíduos Sólidos. Brasília, Brasil: IPEA, 2010. 66 p.

LISBOA. Plano Municipal de Gestão de Resíduos do Município de Lisboa (2015-2020). Lisboa: Câmara Municipal e Direção Municipal de Higiene Urbana. 2016. 102 p.

MARIAPPAN, Nethaji and SELVI, Pynthamizh. GIS based municipal solid waste management solution for Kanchipuram Municipality. Journal of Advanced Research in Civil and Environmental Engineering, 2015, vol. 2, no 3, p. 17-22. Available from: http://technology.adrpublications.com/index.php/JoARCEE/article/view/59/94

Martínez, Clara I. P., and PIÑA, William A. Recycling in Bogotá: A SWOT Analysis of Three Associations to Evaluate the Integrating the Informal Sector into Solid Waste Management. International Journal of Social, Behavioral, Educational, Economic, Business and Industrial Engineering, 2015, vol. 9, № 6, p. 1788-1793. Available from: www.scholar.waset.org/1999.10/10001255

MINISTÉRIO DO MEIO AMBIENTE. Guia para elaboração dos Planos de Gestão de Resíduos Sólidos. Brasília, Brasil: Secretaria de Recursos Hídricos e Ambiente Urbano, 2010. 289 pp.

MUCELLIN, C. A. Lixo e Impactos Ambientais Perceptíveis no Ecossistema Urbano. Sociedade \& Natureza, Junho 2008 , vol. 20, n¹, p. 111-124.

OREA, Domingo G. Ordenación Territorial. 2ª ed.. Madrid: Mundi-Prensa. 2008. ISBN 13:978-84-8476-325-3 
ORNELAS, Odílio Rodrigues. Aplicação de métodos de análise espacial na gestão dos resíduos sólidos urbanos. Belo Horizonte: Instituto de Geociências; Universidade Federal de Minas Gerais, 2011. 101 p. Dissertação de Mestrado em Análise e Modelagem de Sistemas Ambientais.

PARREIRA, Gabriela Fonseca. Coleta seletiva solidária: agregando valor pela integração da cadeia da reciclagem. Belo Horizonte: Escolo de Engenharia; Universidade Federal de Minas Gerais, 2010. 156 p. Dissertação de Mestrado em Engenharia de Produção.

PREFEITURA DE BELO HORIZONTE. Plano Municipal de Saneamento de 2012/2015: Atualização de 2014. Belo Horizonte, Brasil: SUDECAP, 2014 . 127 pp.

PREFEITURA DE BELO HORIZONTE. LEV e URPV. [Em linha]. Belo Horizonte, Brasil: PBH, 2015. [Consultado em 15 outubro de 2015]. Disponível em: http://portalpbh.pbh.gov.br/pbh/ecp/contents.do?evento=conteudo\&idConteudo=132240\&chPlc=132240\&vi $\underline{\text { ewbusca }=\text { s }}$

PREFEITURA DE BELO HORIZONTE. Regional Centro-Sul. [Em linha]. Belo Horizonte, Brasil: PBH, 2015. [Consultado em 15 outubro de 2015]. Disponível em: http://portalpbh.pbh.gov.br/pbh/ecp/comunidade.do?app=regionalcentrosul

POURKARIMI, E., et al. A Conceptual Model for Integrated Management of the Urban Environment in Tehran Metropolis (Based on the Good Governance Guidelines). . Journal of Environmental Research, July 2016, vol. 10, no 3, p. 391-400. Available from: https://ijer.ut.ac.ir/article 58758.html

SILVA, Harley. Aspectos demográficos associados à geração de resíduos domiciliares no município de Belo Horizonte. Belo Horizonte: Faculdade de Ciências Econômicas; Universidade Federal de Minas Gerais, 2002. 203 p. Dissertação de Mestrado em Demografia.

SILVA, Lucia S e TRAVASSOS, Luciana. Problemas Ambientais Urbanos : Desafios para a Elaboração de Políticas Públicas Integradas. Cadernos Metrópole, São Paulo, Brasil, n19, p.27-47.

SILVA, J. W. N.; BARBOSA, A. C. Q. Entre o público e o privado: o modelo de gestão de resíduos sólidos adotado pela SLU de Belo Horizonte. [S.I.]: Escola Nacional de Administração Pública, v. 40, 2001. 26 p

SUPERINTENDÊNCIA DE LIMPEZA URBANA DE BELO HORIZONTE. Relatório Anual de Serviços de Limpeza de 2014. Belo Horizonte, Brasil: SLU-BH, 2014. 77 pp.

SUPERINTENDÊNCIA DE LIMPEZA URBANA DE BELO HORIZONTE. Edital de Licitação Concorrência N002/2015 Que dispõe sobre Prestação de serviços de limpeza urbana, tais como Multitarefa, no Município de Belo Horizonte. [Em linha]. Belo Horizonte, Brasil: Diário Oficial do Município, Ano XXI - Edição N 4808.23 de maio de 2015. [Consultado em 20 de outubro 2015]. Disponível em: http://portal6.pbh.gov.br/dom/iniciaEdicao.do?method=DetalheArtigo\&pk=1142546UNITED NATIONS ENVIRONMENTAL PROGRAMME (UNEP). Developing Integrated Solid Waste Management Plan: Training Manual. 1a ed. v. 4, Osaka/Shiga: International Environmental Technology Centre. 2009. 176 p.

VISMARA, D. Municipal waste management in Milan: separate waste collection in the context of a circular economy in Europe. 2016. [viewed 16 October 2016]. Available From: http://www.municipalwasteeurope.eu/newsitem/presentations-separate-waste-collection-context-circulareconomy-europe

WU, Huanyu et al. An innovative approach to managing demolition waste via GIS (geographic information system): a case study in Shenzhen city, China. Journal of Cleaner Production, January 2016, vol. 112, no 1 p. 494-503. Available from: http://dx.doi.org/10.1016/i.jclepro.2015.08.096 